\title{
Patients with metastatic renal cell carcinoma who benefit from axitinib dose titration: analysis from a randomised, double-blind phase II study
}

Yoshihiko Tomita ${ }^{1 *}$, Hirotsugu Uemura ${ }^{2}$, Mototsugu Oya ${ }^{3}$, Nobuo Shinohara ${ }^{4}$, Tomonori Habuchi ${ }^{5}$, Yosuke Fujii ${ }^{6}$, Yoichi Kamei ${ }^{6}$, Yoshiko Umeyama ${ }^{6}$, Angel H. Bair ${ }^{7}$ and Brian I. Rini ${ }^{8}$

\begin{abstract}
Background: A prospective, randomised phase II study demonstrated clinical benefit of axitinib dose titration in a subset of treatment-naïve patients treated with axitinib for metastatic renal cell carcinoma. This analysis evaluated patient baseline characteristics that may impact overall survival (OS) with axitinib dose titration.

Methods: Following a 4-week lead-in period during which all patients received axitinib 5 mg twice-daily (bid); patients meeting the predefined randomisation criteria were randomly assigned to receive axitinib $5 \mathrm{mg}$ bid plus either axitinib or placebo titration. In exploratory analyses, patients were grouped into those who achieved OS $\geq 24$ versus $<24$ months, and compared their baseline characteristics with Fisher's exact test or Cochran-Armitage trend exact test, with a 5\% significance level. Potential predictive baseline characteristics associated with effect of axitinib dose titration on OS were investigated using a Cox proportional hazard model.

Results: Overall, 112 patients were randomised. Three of 56 patients receiving axitinib titration were censored; of the remaining 53, 33 (62\%) achieved OS $\geq 24$ months versus 20 (38\%) with OS $<24$ months. Patients with OS $\geq 24$ vs. $<24$ months, respectively, had significantly fewer metastatic sites ( $\leq 2$ metastases: $52 \%$ vs. $10 \%$; $\geq 3$ metastases: $48 \%$ vs. $90 \%$ ), fewer lymph node ( $45 \%$ vs. $75 \%$ ) or liver (15\% vs. $45 \%)$ metastases, higher haemoglobin level (i.e., $\geq$ lower limit of normal: $67 \%$ vs. $25 \%$ ) at baseline, lower neutrophil ( $\leq$ upper limit of normal, $97 \%$ vs. $75 \%$ ) and platelet ( $\leq$ upper limit of normal, $82 \%$ vs. $50 \%$ ) levels at baseline and $\geq 1$ year between histopathological diagnosis and treatment (64\% vs. 15\%). The primary reason for treatment discontinuation in both OS groups was disease progression. The frequency of toxicity-related discontinuation was comparable between the 2 groups, indicating that it was not a factor for a shorter OS. The multivariate analysis showed that $\geq 1$ year from histopathological diagnosis to treatment and baseline haemoglobin level equal or greater than lower limit of normal were significant covariates associated with favourable OS in patients receiving axitinib titration.
\end{abstract}

Conclusions: The current analyses identified potentially predictive factors that could help selecting patients who may benefit from axitinib dose titration.

Trial registration: ClinicalTrials.gov identifier, NCT00835978. Registered prospectively, February 4, 2009.

Keywords: Axitinib, Benefit with dose titration, First-line, Metastatic renal cell carcinoma, Predictive factors, Survival benefit

\footnotetext{
* Correspondence: ytomita@med.niigata-u.ac.jp

${ }^{1}$ Department of Urology, Department of Molecular Oncology, Niigata

University Graduate School of Medical and Dental Sciences, Asahimachi

1-757, Niigata 951-8510, Japan

Full list of author information is available at the end of the article
}

(c) The Author(s). 2019 Open Access This article is distributed under the terms of the Creative Commons Attribution 4.0 International License (http://creativecommons.org/licenses/by/4.0/), which permits unrestricted use, distribution, and reproduction in any medium, provided you give appropriate credit to the original author(s) and the source, provide a link to the Creative Commons license, and indicate if changes were made. The Creative Commons Public Domain Dedication waiver (http://creativecommons.org/publicdomain/zero/1.0/) applies to the data made available in this article, unless otherwise stated. 


\section{Background}

Axitinib is a potent and selective inhibitor of vascular endothelial growth factor (VEGF) receptors 1, 2, and 3 approved for second-line treatment in patients with metastatic renal cell carcinoma (mRCC) [1]. Unlike the majority of other targeted agents for cancer treatment, in which dose increase is often not permitted, axitinib starting dose of $5 \mathrm{mg}$ twice daily (bid) can be increased stepwise to $7 \mathrm{mg}$ bid, and to a maximum of $10 \mathrm{mg}$ bid, to improve efficacy outcomes, if patients tolerate the drug. Conversely, the starting dose can be decreased to manage drug-related toxicity.

The effect of axitinib dose titration was prospectively evaluated in a global, randomised phase II study in patients with $\mathrm{mRCC}$ who had not received any prior systemic therapy for the disease [2]. The study results showed a higher proportion of patients who received axitinib dose titration in addition to the starting $5 \mathrm{mg}$ bid dose achieved objective response compared with those who received placebo titration plus the starting dose ( $5 \mathrm{mg}$ bid) of axitinib (54\% vs. $34 \%$, respectively; 1 -sided $p=0.019$ ), thus providing evidence for clinical benefit of individualised axitinib dose titration in some patients. A follow-up analysis indicated a numerically longer overall survival (OS) in the axitinib dose titration arm compared with placebo titration arm (median OS, 42.7 vs. 30.4 months; 1 -sided $p=0.162$ ), without any new safety concerns [3]. It was noted in the study that the Kaplan-Meier curves for OS estimates for the axitinib dose titration and placebo titration arms appeared to cross over at approximately 24 months following treatment initiation (Fig. 1) [3]. This phenomenon might have been attributed to a random occurrence, but it could also have been the summation of various clinical responses following axitinib dose titration. For instance, some patients in the axitinib titration arm might have discontinued treatment early due to drug-related toxicities as a result of aggressive dose increase. It might also be plausible that in patients with poor baseline prognosis, tumours could have rapidly progressed before achieving the therapeutic level of axitinib with dose titration. Whatever the reason(s) may be for the crossover, it is likely that patients who had OS $\geq 24$ months had attained clinical benefits with axitinib dose titration.

The current analysis was conducted to evaluate patient baseline characteristics that may be associated with longer OS in patients treated with axitinib dose titration, which would help identify patients who potentially benefit from axitinib dose titration.

\section{Methods}

\section{Study design}

The data used in the current analysis were from the randomised, double-blind phase II study of axitinib dose titration conducted in 6 countries (Czech Republic, Germany, Japan, Russia, Spain and the United States). Details of the study design (Fig. 2) and the results of the primary endpoint, which was comparison of the percentage of patients who achieved an objective response between randomised arms, have been previously published [2].

The study was conducted in accordance with the Declaration of Helsinki, the International Conference on Harmonisation guidelines on Good Clinical Practice,

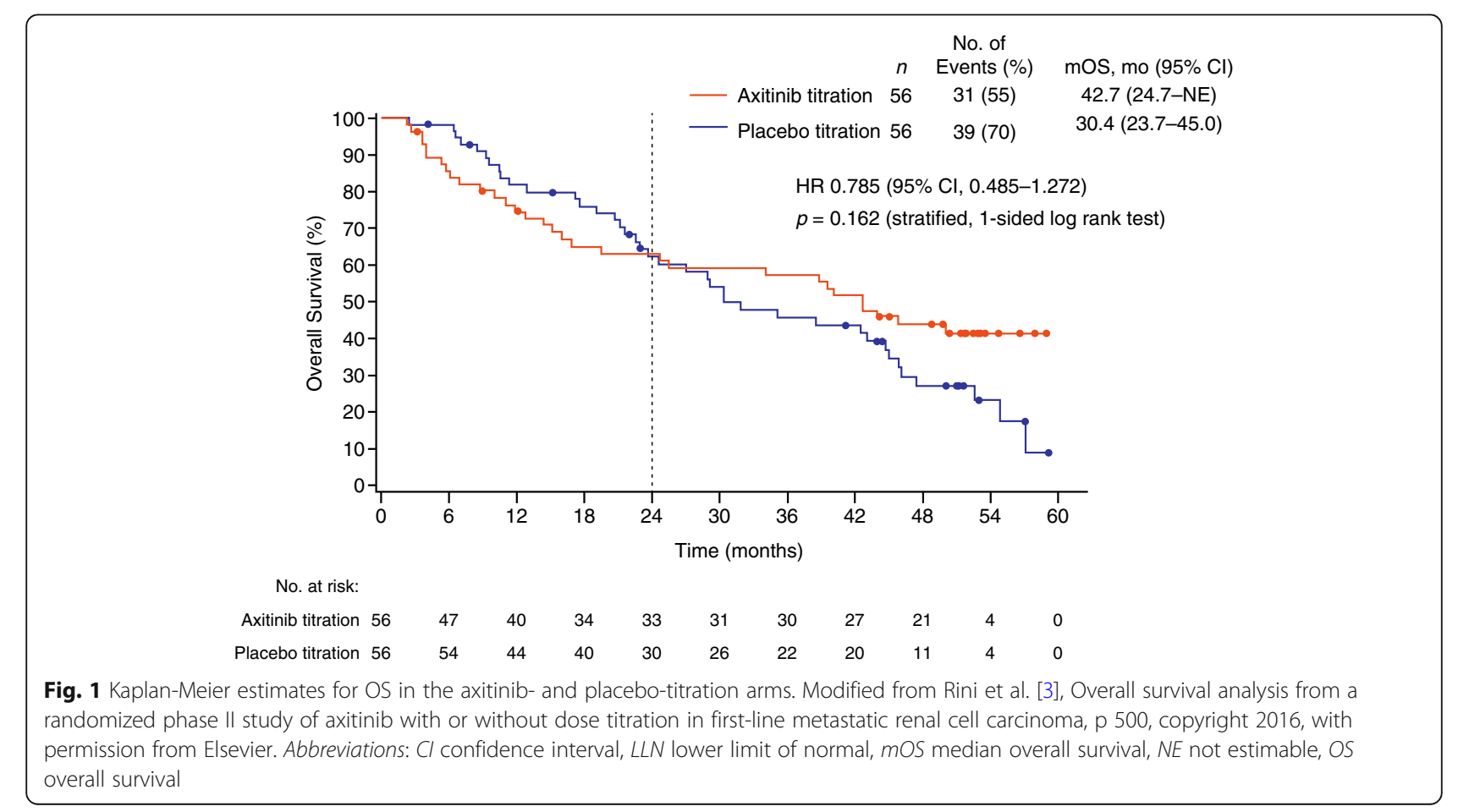




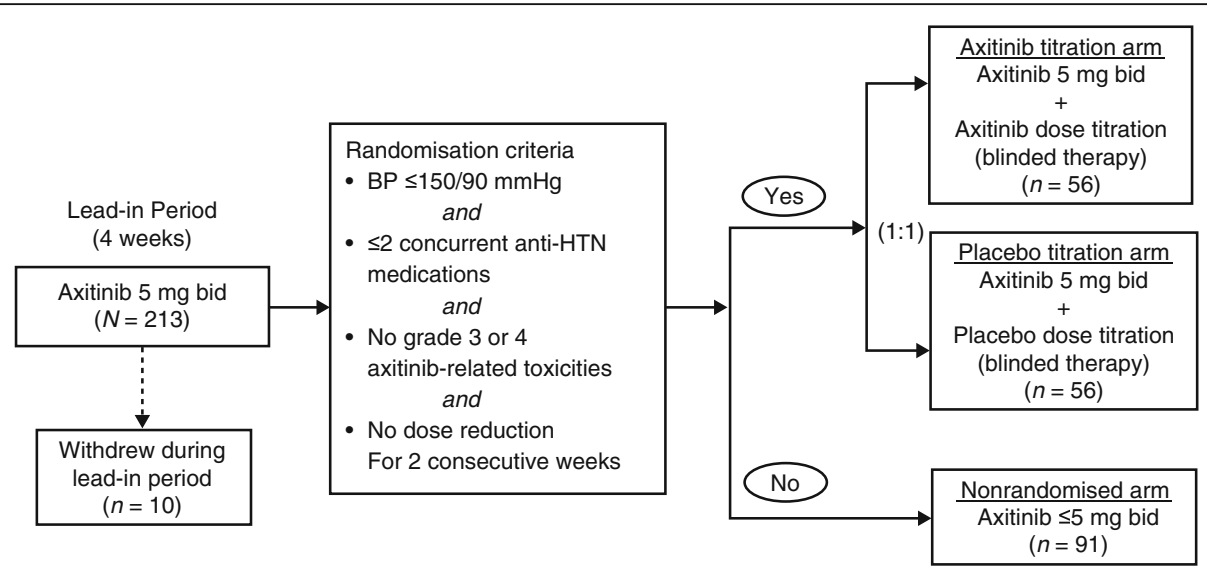

Fig. 2 Study design [8]. Abbreviations: bid twice daily; BP blood pressure; HTN hypertension

and all applicable local regulations and laws. The study protocol and patient informed consent form were approved by the institutional review board or independent ethics committee at each centre, and each patient provided written informed consent prior to study entry. This trial is registered at ClinicalTrials.gov (identifier NCT00835978).

\section{Patients and treatment}

Inclusion and exclusion criteria have been described in detail elsewhere [2]. In brief, key eligibility included histologically confirmed mRCC with a clear cell component based on laboratory assessments conducted at each site; $\geq 1$ measurable disease by Response Evaluation Criteria in Solid Tumours (RECIST) v1.0; no prior systemic therapy for mRCC; Eastern Cooperative Oncology Group performance status (ECOG PS) 0 or 1 ; and no uncontrolled hypertension (blood pressure [BP] $\leq 140 / 90 \mathrm{mmHg}$ ).

All eligible patients received the axitinib $5 \mathrm{mg}$ bid starting dose during a 4-week lead-in period, after which patients were randomly assigned to axitinib or placebo titration if they had met the randomisation criteria for 2 consecutive weeks: BP $\leq 150 / 90 \mathrm{mmHg}$; no grade 3 or 4 drug-related adverse events (AEs), according to the Common Terminology Criteria for Adverse Events v3.0; no axitinib dose reduction; and use of $\leq 2$ concurrent antihypertensive medications. Patients in both titration arms had their daily dose of axitinib or placebo increased by $2 \mathrm{mg}$ bid in a blinded fashion, to a total of 7 $\mathrm{mg}$ bid. If patients tolerated the drug at this dose by meeting the randomisation criteria, the dose could be further increased to the maximum total dose of $10 \mathrm{mg}$ bid (including the axitinib 5-mg starting dose). Patients who did not meet the randomisation criteria continued treatment in a nonrandomised arm.

\section{Assessments and statistical analyses}

Radiologic tumour assessments were performed by investigators at baseline, weeks 8,16 , and 24, and every 12 weeks thereafter, according to RECIST. Survival data were collected every 3 months after the last follow-up visit, which was 28 days after the last dose.

In exploratory analyses, patients in the axitinib or placebo titration arm were grouped into those with a longer OS (i.e., OS $\geq 24$ months) versus shorter OS (i.e., OS $<24$ months). A cutoff of 24 months was chosen because it was the time period at which there was a crossover of the OS curves between the axitinib and placebo titration arms. Demographics and baseline characteristics of patients who with OS $\geq 24$ months versus $<24$ months in the axitinib or placebo titration arm were compared with Fisher's exact test for binary categorical variables or Cochran-Armitage trend exact test for ordinal categorical variables, with a 5\% significance level.

For selected baseline characteristics, a multivariate analysis using a Cox proportional hazard model was subsequently conducted to investigate the potential predictive baseline characteristics associated with the effect of axitinib dose titration on OS. This analysis was performed for all randomised patients in both the axitinib and placebo titration arms to evaluate the interaction effects between axitinib/placebo titration and baseline characteristics on OS. Median OS and 95\% confidence intervals (CIs) for potential predictive baseline characteristics were estimated using the Kaplan-Meier method.

\section{Results}

Patients

Of 112 patients who met the randomisation criteria, 56 each were randomly assigned to the axitinib and placebo titration arms. Patient disposition in the randomised arms is summarised in Table 1. 
Table 1 Patient disposition in the axitinib and placebo titration arms

\begin{tabular}{lll}
\hline Disposition, $n$ (\%) & $\begin{array}{l}\text { Axitinib Titration } \\
n=56\end{array}$ & $\begin{array}{l}\text { Placebo Titration } \\
n=56\end{array}$ \\
\hline Discontinued treatment & $47(84)$ & $55(98)$ \\
Disease progression/relapse & $35(63)$ & $40(71)$ \\
Adverse event & $8(14)$ & $5(9)$ \\
Death & $2(4)$ & $1(2)$ \\
$\begin{array}{l}\text { Refusal of treatment for reason } \\
\text { other than adverse event }\end{array}$ & $1(2)$ & $4(7)$ \\
$\begin{array}{l}\text { Global deterioration in health } \\
\text { status }\end{array}$ & $1(2)$ & $1(2)$ \\
Protocol violation & 0 & $1(2)$ \\
Other & 0 & $3(5)$ \\
Remaining on treatment & $9(16)$ & $1(2)$ \\
\hline
\end{tabular}

In the axitinib titration arm, 3 patients who were censored $<24$ months in OS, were excluded from the dataset; the remaining 53 patients were included in the analysis. Of these, 33 (62\%) patients achieved OS $\geq 24$ months, whereas 20 (38\%) had OS < 24 months. Comparison of demographics and baseline characteristics between axitinib-titrated patients who achieved OS $\geq 24$ versus $<24$ months, respectively, showed that patients with a longer OS had significantly fewer metastatic sites ( $\leq 2$ metastases: $52 \%$ vs. $10 \%$; $\geq 3$ metastases: $48 \%$ vs. $90 \%)$, fewer lymph node (45\% vs. $75 \%$ ) or liver (15\% vs. $45 \%)$ metastases at baseline, longer time between histopathological diagnosis and treatment ( $\geq 1$ year: $64 \%$ vs. $15 \%)$, higher than lower limit of normal (LLN) baseline haemoglobin levels (67\% vs. $25 \%)$, lower than upper limit of normal (ULN) baseline neutrophil levels (97\% vs. $75 \%$ ), and lower than ULN baseline platelet levels (82\% vs. 50\%) (Table 2). Although a higher percentage of patients with $\mathrm{OS} \geq 24$ months relative to those with OS $<24$ months received prior nephrectomy ( $97 \%$ vs. $80 \%$ ) or had fewer bone metastases (6\% vs. $25 \%$ ) at baseline, the difference did not reach a statistical significance. There was no significant difference in baseline ECOG PS, histological classification, or tumour size between the 2 groups (Table 2).

In the placebo titration arm, 6 patients were censored < 24 months in OS and excluded from the analysis; of the remaining 50 patients, $30(60 \%)$ achieved OS $\geq 24$ months, and $20(40 \%)$ had OS < 24 months. No significant difference was observed in demographics or baseline characteristics of placebo-titrated patients with $\mathrm{OS} \geq 24$ versus $<24$ months in the placebo titration arm (Additional file 1).

\section{Treatment}

Patients in the axitinib titration arm with $\mathrm{OS} \geq 24$ versus $<24$ months, respectively, received comparable average daily doses of axitinib (median: 13.9 vs. $13.0 \mathrm{mg}$ ) and median relative dose intensity was similar (135\% vs. $125 \%$ ) (Table 3). As expected, patients who achieved OS $\geq 24$ months received axitinib treatment for a significantly longer period than those with OS $<24$ months. Median number of days from date of the first dose to date of the last dose or data cutoff was 925 days in patients with OS $\geq 24$ months versus 85 days in patients with OS $<24$ months; median number of days in which axitinib was administered was 925 and 84 days, respectively. In the placebo titration arm, patients with OS $\geq 24$ months also received treatment for a longer period than those with OS $<24$ months (Additional file 2).

At the data cutoff date, 24 (73\%) and 20 (100\%) axitinib-titrated patients who achieved OS $\geq 24$ versus $<24$ months, respectively, had discontinued treatment. Although the primary reason for treatment discontinuation was disease progression, it is notable that the percentage of patients who progressed was lower in the OS $\geq 24$ versus < 24 months groups ( $52 \%$ vs. $80 \%$, respectively; Table 4 ). The frequency of discontinuation due to AEs was generally comparable between OS $\geq 24$ and $<24$ months ( $15 \%$ vs. $10 \%)$. Reasons for treatment discontinuation in the placebo titration arm were similar to those in the axitinib titration arm, with disease progression being the primary reason (Additional file 3).

\section{Safety}

In the axitinib titration arm, the common treatmentemergent, all-causality, all-grade AEs reported by > $50 \%$ of patients included diarrhoea, hypertension, and fatigue in the OS $\geq 24$-months group, and hypertension and nausea in the OS <24-months group (Table 5). The nature of AEs reported by patients with $\mathrm{OS} \geq 24$ months was similar to those with OS $<24$ months, but incidence rates of diarrhoea, hypertension, hypothyroidism, handfoot syndrome, and stomatitis were substantially (>20\%) higher in patients with $\mathrm{OS} \geq 24$ months than OS $<24$ months. Hypertension was the frequently reported grade 3 or $4 \mathrm{AE}$ in either group. The nature and severity of AEs in patients with $O S \geq 24$ and $O S<24$ months in the placebo titration arm were generally similar to those in the corresponding OS groups in the axitinib titration arm (Additional file 4).

\section{Predictive factors for survival benefit with axitinib dose titration}

In the multivariate analysis conducted using the data from all 112 randomised patients, time from histopathological diagnosis to treatment $\geq 1$ year and baseline haemoglobin level $\geq$ LLN were found to be independent and significant ( $p<0.1$ for interaction) predictive covariates associated with favourable OS in the axitinib titration arm, whereas a trend for association was observed with the number of metastatic 
Table 2 Baseline characteristics of patients with OS $\geq 24$ versus $<24$ months in the axitinib titration arm

\begin{tabular}{|c|c|c|c|c|}
\hline Baseline Characteristics, $n$ (\%) & & OS $\geq 24$ months $n=33$ & OS $<24$ months $n=20^{a}$ & $p$-value ${ }^{b}$ \\
\hline \multirow[t]{2}{*}{ Age, years } & $<65$ & $19(58)$ & $17(85)$ & 0.0670 \\
\hline & $\geq 65$ & $14(42)$ & $3(15)$ & \\
\hline \multirow[t]{2}{*}{ Sex } & Male & $21(64)$ & $15(75)$ & 0.5457 \\
\hline & Female & $12(36)$ & $5(25)$ & \\
\hline \multirow[t]{3}{*}{ Race } & White & $28(85)$ & $18(90)$ & 0.2672 \\
\hline & Asian & $5(15)$ & $1(5)$ & \\
\hline & Other & 0 & $1(5)$ & \\
\hline \multirow[t]{4}{*}{ Weight, kg } & $\leq 65$ & $7(21)$ & $5(25)$ & 1.0000 \\
\hline & $>65, \leq 76$ & $12(36)$ & $7(35)$ & \\
\hline & $>76, \leq 89$ & $8(24)$ & $3(15)$ & \\
\hline & $>89$ & $6(18)$ & $5(25)$ & \\
\hline \multirow[t]{2}{*}{ ECOG PS } & 0 & $23(70)$ & $11(55)$ & 0.3775 \\
\hline & $\geq 1$ & $10(30)$ & $9(45)$ & \\
\hline \multirow[t]{2}{*}{ Histological classification } & Clear cell & $33(100)$ & $18(90)$ & 0.1379 \\
\hline & Other $^{c}$ & 0 & $2(10)$ & \\
\hline \multirow[t]{2}{*}{ Prior nephrectomy } & Yes & $32(97)$ & $16(80)$ & 0.0611 \\
\hline & No & $1(3)$ & $4(20)$ & \\
\hline \multirow[t]{2}{*}{ No. of metastatic sites } & $\leq 2$ & $17(52)$ & $2(10)$ & 0.0028 \\
\hline & $\geq 3$ & $16(48)$ & $18(90)$ & \\
\hline \multirow[t]{2}{*}{ Site of metastasis } & Lung only & $4(12)$ & 0 & 0.2848 \\
\hline & Lung + others & $29(88)$ & $20(100)$ & \\
\hline \multicolumn{5}{|l|}{ Site of metastasis, individual } \\
\hline & Lung & $19(58)$ & $16(80)$ & 0.1368 \\
\hline & Lymph node & $15(45)$ & $15(75)$ & 0.0476 \\
\hline & Kidney & $7(21)$ & $4(20)$ & 1.0000 \\
\hline & Liver & $5(15)$ & $9(45)$ & 0.0252 \\
\hline & Adrenal & $10(30)$ & $4(20)$ & 0.5274 \\
\hline & Bone & $2(6)$ & $5(25)$ & 0.0896 \\
\hline & Pancreas & $2(6)$ & 0 & 0.5210 \\
\hline \multicolumn{5}{|c|}{ Time from histopathological diagnosis to treatment } \\
\hline & $\geq 1$ year & $21(64)$ & $3(15)$ & 0.0007 \\
\hline & $<1$ year & $12(36)$ & $17(85)$ & \\
\hline \multicolumn{5}{|c|}{ Time from metastatic diagnosis to treatment } \\
\hline & $\geq 1$ year & $4(12)$ & $1(5)$ & 0.6388 \\
\hline & $<1$ year & $29(88)$ & $19(95)$ & \\
\hline \multicolumn{5}{|c|}{ Sum of longest diameter for target lesion } \\
\hline & $\leq$ Median & $17(52)$ & $7(35)$ & 0.2702 \\
\hline & $>$ Median & $16(48)$ & $13(65)$ & \\
\hline \multicolumn{5}{|c|}{ Presence of metastases (de novo) at initial diagnosis } \\
\hline & No & $22(67)$ & $12(60)$ & 0.7689 \\
\hline & Yes & $11(33)$ & $8(40)$ & \\
\hline \multirow[t]{2}{*}{ Baseline LDH } & $\leq 1.5 \times \cup L N$ & $33(100)$ & $18(90)$ & 0.1379 \\
\hline & $>1.5 \times U L \mathrm{LN}$ & 0 & $2(10)$ & \\
\hline
\end{tabular}


Table 2 Baseline characteristics of patients with OS $\geq 24$ versus $<24$ months in the axitinib titration arm (Continued)

\begin{tabular}{|c|c|c|c|c|}
\hline \multicolumn{2}{|c|}{ Baseline Characteristics, $n$ (\%) } & \multirow{2}{*}{$\frac{\text { OS } \geq 24 \text { months } n=33}{22(67)}$} & \multirow{2}{*}{$\begin{array}{l}\text { OS }<24 \text { months } n=20^{a} \\
5(25)\end{array}$} & \multirow{2}{*}{$\frac{p \text {-value }}{0.0047}$} \\
\hline Baseline $\mathrm{Hb}$ & $\geq \mathrm{LLN}$ & & & \\
\hline & $<L L N$ & $11(33)$ & $15(75)$ & \\
\hline \multirow[t]{2}{*}{ Baseline Neu } & $\leq \cup\llcorner N$ & $32(97)$ & $15(75)$ & 0.0240 \\
\hline & $>U L N$ & $1(3)$ & $5(25)$ & \\
\hline \multirow[t]{2}{*}{ Baseline Plt } & $\leq \cup L N$ & $27(82)$ & $10(50)$ & 0.0288 \\
\hline & $>U L N$ & $6(18)$ & $10(50)$ & \\
\hline
\end{tabular}

Abbreviations: ECOG PS Eastern Cooperative Oncology Group performance status, $H b$ haemoglobin, $L D H$ lactate dehydrogenase, $L L N$ lower limit of normal, Neu neutrophil, OS overall survival, Plt platelet, ULN upper limit of normal

${ }^{a}$ Excluded 3 patients who were censored $<24$ months in OS

${ }^{\mathrm{b}}$ Fisher's exact test was used for all, except weight, for which Cochran-Armitage trend test was used

'Other includes sarcomatoid and clear cell with sarcomatoid differentiation in 1 patient each

sites (Table 6). Baseline neutrophil and platelet levels were excluded from the multivariate analysis due to the limited number of patients with $>$ ULN. The presence of $\leq 2$ metastatic sites was associated with longer OS with axitinib titration and placebo titration (hazard ratio [HR] 2.191 and 4.438; $p=0.0179$ ), but the interaction was not significant $(p=0.2321$, Additional file 5). There was no difference for OS between $<1$ versus $\geq 1$ year from histopathological diagnosis to treatment with placebo titration (HR 1.437; $p=$ 0.3218 ), whereas there was significant interaction with axitinib titration (HR 3.569; $p=0.0900$ for interaction). Similarly, baseline haemoglobin level $\geq$ LLN was associated with longer OS in patients receiving axitinib titration (HR 3.378; $p=0.0126$ for interaction), but not in patients in the placebo titration arm (HR 0.940; $p=0.8543)$ (Additional file 5).

To visually evaluate the potential effect of axitinib dose titration on each covariate for OS (i.e., predictive value of each covariate for OS), median OS was estimated in the axitinib and placebo titration arms following stratification by the individual covariate identified as significant in the multivariate analysis. Median follow-up for OS in all 112 randomised patients was 30.4 months. In the axitinib titration arm, median OS $(95 \% \mathrm{CI})$ was not

Table 3 Drug exposure in patients with OS $\geq 24$ versus $<24$ months in the axitinib titration arm

\begin{tabular}{lll}
\hline Parameter & $\begin{array}{l}\text { OS } \geq 24 \text { months } \\
n=33\end{array}$ & $\begin{array}{l}\text { OS }<24 \text { months } \\
n=20^{\mathrm{a}}\end{array}$ \\
\hline Days on treatment, ${ }^{\mathrm{b}}$ median (range) & $925(106-1795)$ & $85(42-456)$ \\
$\begin{array}{l}\text { Days on drug, }{ }^{\mathrm{C}} \text { median (range) } \\
925(91-1688)\end{array}$ & $84(38-456)$ \\
$\begin{array}{l}\text { Average daily dose, median } \\
\text { (range), mg }\end{array}$ & $13.9(4.9-23.4)$ & $13.0(9.9-19.2)$ \\
$\begin{array}{l}\text { Relative dose intensity, median } \\
\text { (range), \% }\end{array}$ & $135(46-224)$ & $125(83-192)$ \\
$\begin{array}{l}\text { Patients with dose decrease }<5 \mathrm{mg} \\
\text { bid, } n \text { (\%) }\end{array}$ & $10(30)$ & $1(5)$ \\
\hline
\end{tabular}

Abbreviations: bid twice daily, OS overall survival

${ }^{a}$ Excluded 3 patients who were censored $<24$ months in OS

${ }^{\mathrm{b}}$ Time period starting from date of the first dose to date of the last dose or data cutoff

${ }^{\mathrm{c}}$ Total number of days in which axitinib was actually administered estimable ( 42.7 months-not estimable) in patients with $\geq 1$ year between histopathological diagnosis and treatment compared with $16.0(11.1-42.8)$ months in patients treated $<1$ year post diagnosis (Fig. 3a), whereas in the placebo titration arm, median OS was 35.2 (23.7-not estimable) versus 30.4 (21.6-45.0) months ( $\geq 1$ vs. $<1$ year, respectively).

Similarly, in patients with $\geq \mathrm{LLN}$ baseline haemoglobin level, median OS $(95 \% \mathrm{CI})$ in the axitinib titration arm was not estimable (40.1 months-not estimable) compared with 16.9 (11.1-44.0) months in those with <LLN baseline levels (Fig. 3b), whereas no notable difference was found in patients in the placebo titration arm: 31.9 (23.7-44.7) vs. 27.1 (17.2-54.8) months. When stratified by number of metastatic sites, median OS $(95 \% \mathrm{CI})$ in patients in the axitinib titration arm who had $\leq 2$ metastatic sites was not estimable (not estimable-not estimable) compared with 19.6 (11.9-42.8) months in patients with $\geq 3$ metastatic sites. In the placebo titration arm, patients with $\leq 2$ metastatic sites also had a longer median OS than those with $\geq 3$ metastatic sites: 46.1 (30.4-57.2) vs. 24.6 (11.4-31.9) months, respectively (Fig. 3c).

Not surprisingly, in both the axitinib and placebo titration arms, median progression-free survival (PFS) was shorter in patients with OS $<24$ months than in patients with OS $\geq 24$ months (Fig. 4).

Table 4 Reasons for treatment discontinuation of patients with OS $\geq 24$ versus $<24$ months in the axitinib titration arm

\begin{tabular}{lll}
\hline $\begin{array}{l}\text { Reason for treatment } \\
\text { discontinuation, } n(\%)\end{array}$ & $\begin{array}{l}\text { OS } \geq 24 \text { months } \\
n=33^{\mathrm{a}}\end{array}$ & $\begin{array}{l}\text { OS }<24 \text { months } \\
n=20^{\mathrm{b}}\end{array}$ \\
\hline Objective progression or relapse & $\begin{array}{l}17(52) \\
\text { Adverse event }\end{array}$ & $\begin{array}{l}5(15) \\
2(10)\end{array}$ \\
$\begin{array}{l}\text { Death } \\
\text { Global deterioration of health status }\end{array}$ & 0 & $1(5)$ \\
$\begin{array}{l}\text { Patient refusal to continue treatment } \\
\text { for reason other than adverse event }\end{array}$ & $1(3)$ & $1(5)$ \\
Total & $24(73)$ & 0 \\
\hline
\end{tabular}

Abbreviation: OS overall survival

ancluding 9 patients still on treatment

${ }^{\mathrm{b}}$ Excluded 3 patients who were censored $<24$ months in OS 
Table 5 Common, all-causality adverse events reported in patients with OS $\geq 24$ versus $<24$ months in the axitinib titration arm

\begin{tabular}{|c|c|c|c|c|}
\hline \multirow[t]{2}{*}{ Adverse event, ${ }^{a} n(\%)$} & \multicolumn{2}{|c|}{$\begin{array}{l}\text { OS } \geq 24 \text { months } \\
n=33\end{array}$} & \multicolumn{2}{|c|}{$\begin{array}{l}\text { OS }<24 \text { months } \\
n=20^{\mathrm{b}}\end{array}$} \\
\hline & All Grades & Grade $\geq 3$ & All Grades & Grade $\geq 3$ \\
\hline Any & $33(100)$ & $24(73)$ & $19(95)$ & $11(55)$ \\
\hline Diarrhoea & $27(82)$ & $7(21)$ & $7(35)$ & 0 \\
\hline Hypertension & $24(73)$ & $7(21)$ & $10(50)$ & $3(15)$ \\
\hline Fatigue & $18(55)$ & $1(3)$ & $9(45)$ & $2(10)$ \\
\hline Nausea & $14(42)$ & $1(3)$ & $10(50)$ & $2(10)$ \\
\hline Hand-foot syndrome & $14(42)$ & $1(3)$ & $4(20)$ & $1(5)$ \\
\hline Hypothyroidism & $14(42)$ & 0 & $4(20)$ & 0 \\
\hline Decreased appetite & $12(36)$ & $2(6)$ & $8(40)$ & $2(10)$ \\
\hline Weight decrease & $12(36)$ & $6(18)$ & $4(20)$ & 0 \\
\hline Vomiting & $11(33)$ & $3(9)$ & $8(40)$ & $1(5)$ \\
\hline Dysphonia & $11(33)$ & 0 & $7(35)$ & $1(5)$ \\
\hline Arthralgia & $10(30)$ & 0 & $3(15)$ & $1(5)$ \\
\hline Stomatitis & $10(30)$ & $1(3)$ & 0 & 0 \\
\hline Mucosal inflammation & $9(27)$ & $1(3)$ & $3(15)$ & $1(5)$ \\
\hline Proteinuria & $9(27)$ & $2(6)$ & $3(15)$ & 0 \\
\hline
\end{tabular}

Abbreviation: OS overall survival

${ }^{\mathrm{a}}$ Reported by $\geq 25 \%$ in either group

${ }^{b}$ Excluded 3 patients who were censored $<24$ months in OS

\section{Discussion}

With several VEGF- and other molecular-targeted agents, including axitinib, which are available as monotherapy and/or in sequential therapy, survival rates for patients with mRCC have drastically increased in the past decade. However, not all patients benefit from these targeted agents and, therefore, identification and validation of biomarkers that may facilitate selection of patients who would achieve clinical benefit from individual targeted agents has become one of the critical challenges in the treatment algorithm for mRCC. Although several studies have reported a number of patient baseline characteristics as potential biomarkers for PFS and/or OS in patients with mRCC treated with targeted therapy [4-7], none to date have been validated for use in a routine clinical setting. This study investigated patient baseline characteristics that

Table 6 Multivariate analysis of patient baseline characteristics for the effect of interaction with axitinib titration on OS

\begin{tabular}{lll}
\hline Parameter & \multicolumn{2}{l}{ HR for Covariate } \\
\cline { 2 - 3 } & $\begin{array}{ll}\text { Placebo } \\
\text { Titration }\end{array}$ & $\begin{array}{c}\text { Axitinib } \\
\text { Titration }\end{array}$ \\
\hline Metastatic site ( $\geq 3$ vs. $\leq 2)$ & 2.191 & 4.438 \\
Time from histopathological diagnosis & 1.437 & 3.569 \\
to treatment (<1 vs. $\geq 1$ year) & & \\
Baseline Hb $<$ LLN (yes vs. no) & 0.940 & 3.378 \\
\hline
\end{tabular}

Abbreviations: $\mathrm{Cl}$ confidence interval, $\mathrm{Hb}$ haemoglobin, $H R$ hazard ratio, $L L N$ lower limit of normal may render survival benefit with axitinib dose titration in the first-line setting for patients with mRCC.

The current analyses revealed several interesting findings. Among 56 treatment-naïve patients with $\mathrm{mRCC}$ who were randomly assigned to the axitinib titration arm, 33 attained OS $\geq 24$ months and 20 did not. Patients with OS $\geq 24$ months had more favourable baseline characteristics and received a significantly longer duration of treatment than patients with OS $<24$ months. The discontinuations due to AEs were not a factor for the shorter OS since the frequency of AE-related discontinuations was comparable between the 2 groups. Although the incidence of diarrhoea, hypertension, hypothyroidism, hand-foot syndrome, and stomatitis were substantially greater in patients with $\mathrm{OS} \geq 24$ months than OS $<24$ months, this may be a reflection of the longer treatment duration that patients with $O S \geq 24$ months received compared with patients with OS $<24$ months. It should be pointed out that in the OS $<24$ months group, more than $50 \%$ of patients developed disease progression by approximately 3 months, leading to a shorter treatment duration in this group.

In the multivariate analysis, time from histopathological diagnosis to treatment $\geq 1$ year was associated with longer OS with axitinib titration, whereas there was no significant difference between $<1$ versus $\geq 1$ year with placebo titration. Similarly, baseline haemoglobin level $\geq$ LLN was associated with longer $\mathrm{OS}$ in patients receiving axitinib titration, but not in patients in the placebo titration arm. These results suggest that time between diagnosis and treatment and baseline haemoglobin level may potentially serve as predictive baseline characteristics for OS with axitinib titration. As for the number of metastatic sites, OS was different between patients with $\geq 3$ versus $\leq 2$ metastatic sites at baseline in the axitinib titration arm, but this trend was also seen in the placebo titration arm, indicating that number of metastatic sites is a prognostic factor for OS, although it potentially has a predictive value for OS with axitinib titration.

Tomita and his colleagues previously reported the results of a multivariate analysis for predictive factors of PFS, which was based on the same dose titration study but used data from all 213 patients enrolled in the study [8]. That analysis identified time from diagnosis to treatment and baseline tumour size as independent predictive factors for PFS. In another multivariate analysis, Oya et al. identified longer time from histopathological diagnosis to treatment, lower baseline tumour burden, and lower baseline ECOG PS as positive predictors of OS [9]. Time from diagnosis to treatment was the common predictive factor for OS found by both Oya et al. and the current analysis, whereas baseline tumour burden and ECOG PS were unique to the analysis by Oya et al. and baseline haemoglobin level was unique to the current 


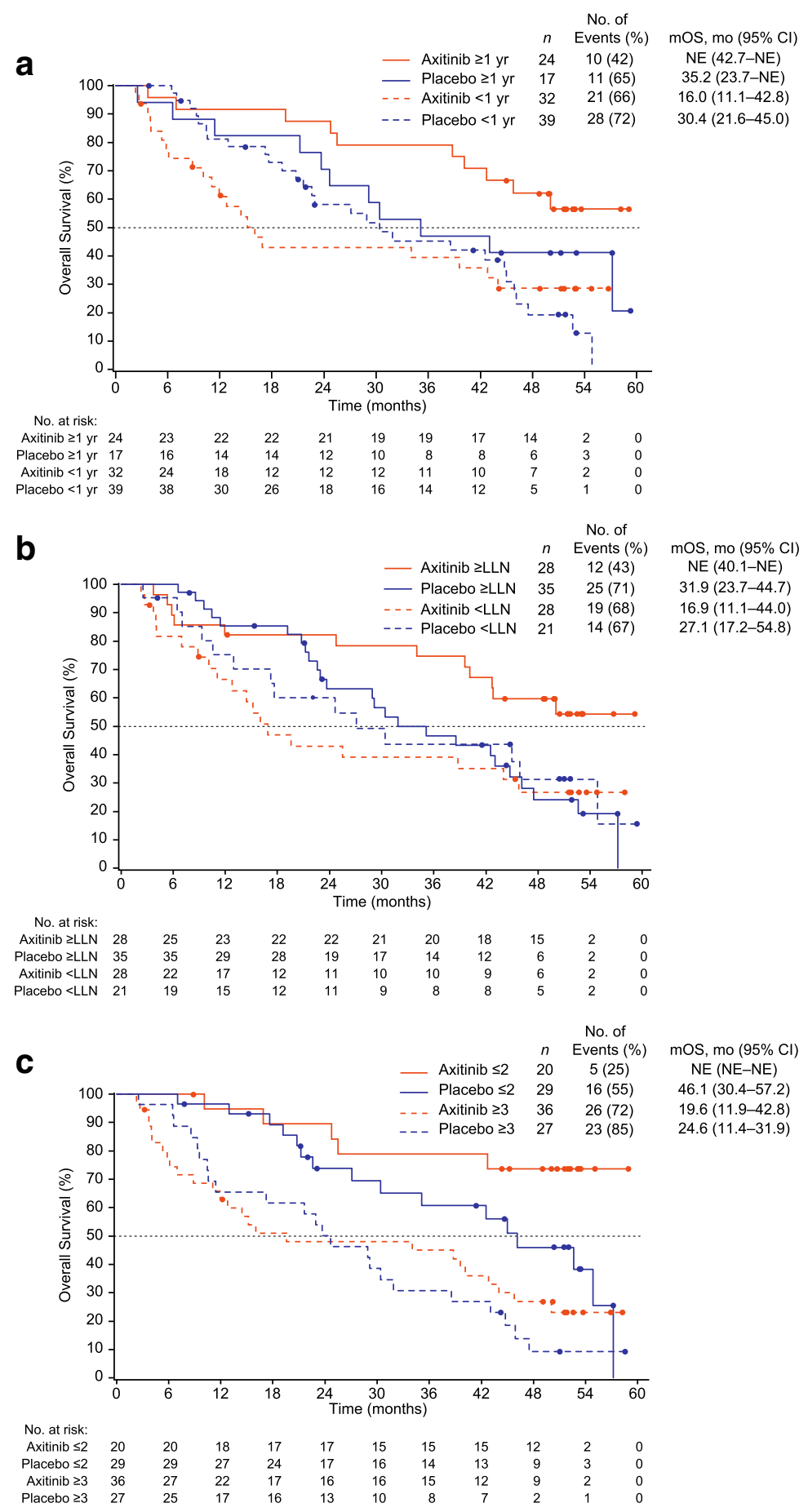

Fig. 3 Kaplan-Meier estimates for OS in the axitinib- and placebo-titration arms. (a) Stratified by time from histopathological diagnosis to treatment, (b) stratified by baseline haemoglobin level, and (c) stratified by number of metastatic sites. Abbreviations: Cl confidence interval, LLN lower limit of normal, mOS median overall survival, NE not estimable, OS overall survival

analysis. A possible reason for differences in factors predictive of better OS or PFS among the 3 analyses may be attributable to the difference in the datasets used, i.e., 213 patients, including 10 patients who discontinued prior to randomisation as well as 91 patients who were not randomised, in the previous 2 analyses compared with 112 randomised patients in the current analysis. It may also be explained, at least in part, by the methodological differences: the current analysis evaluated the effect of axitinib versus placebo titration on OS and, 


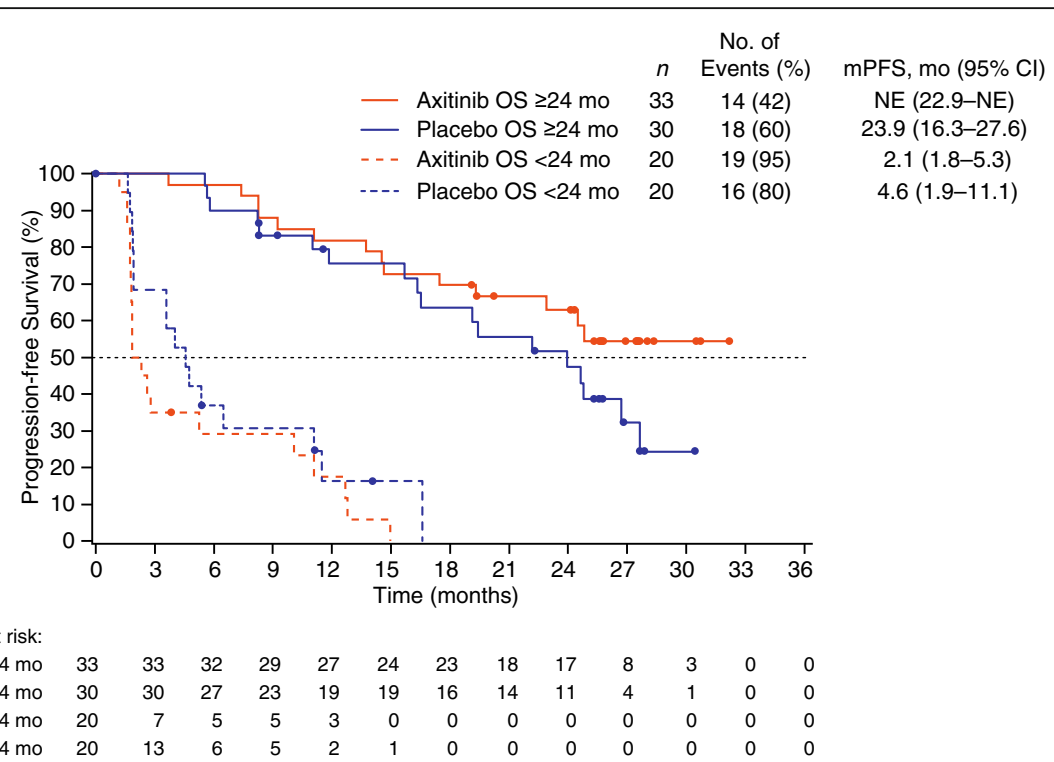

Fig. 4 Kaplan-Meier estimates for PFS in the axitinib- and placebo-titration arms stratified by OS. Patients were stratified by OS $\geq 24$ vs. $<24$ months. Abbreviations: Cl confidence interval, mPFS median progression-free survival, NE not estimable, OS overall survival

additionally, investigated the effect of interaction between axitinib dose titration and the covariate effect on OS, which was not conducted previously. The predictive factors identified for clinical benefit of axitinib in these 3 analyses are not completely the same, but all are related to better prognosis for patients at baseline. Therefore, it has been postulated that patients with more favourable baseline characteristics would preferentially receive PFS and OS benefit from axitinib treatment and OS benefit from axitinib dose titration.

The Memorial Sloan Kettering Cancer Center (MSKCC) and the International Metastatic Renal-Cell Carcinoma Database Consortium (IMDC) risk factors have been established and validated for classification of baseline prognosis in patients with $\mathrm{mRCC}$ treated with cytokines or VEGF-targeted agents [4-7]. Many of these MSKCC and IMDC risk factors have been confirmed in the multivariate analysis for baseline prognostic factors for OS in the phase III trial of axitinib in patients previously treated with systemic therapy for mRCC [10]. In that analysis, time from diagnosis to treatment and baseline haemoglobin level, which were identified in our analysis, were found among the prognostic factors. With regard to haemoglobin, it is worth mentioning that in a retrospective multivariate analysis conducted in 1463 Japanese patients with mRCC, a low baseline level of haemoglobin was correlated with a high baseline level of C-reactive protein, and the high level of C-reactive protein at the metastatic diagnosis was significantly associated with poor prognosis [11]. Although that analysis was performed using data from the cytokine era, similar observations regarding the potential prognostic value of C-reactive protein have been reported in patients with $\mathrm{mRCC}$ treated with targeted therapies [12,13].

It is interesting that in the validation study for the MSKCC risk criteria, Motzer and his colleagues also analysed baseline characteristics predictive of long-term OS, defined as OS $\geq 30$ months, in sunitinib-treated patients with $\mathrm{mRCC}$ [6]. A number of baseline characteristics, including ethnic origin, MSKCC risk factors, ECOG PS, and prior nephrectomy, differed significantly between patients with long-term OS $(n=215)$ and nonlong-term OS $(n=844)$. The multivariate analysis found ethnic origin, baseline bone metastases, and corrected calcium levels to be independent prognostic factors in patients with long-term OS. Possible reasons for the differences between the results by Motzer et al. and the current analysis may be the difference in sample size and/ or time used as a cutoff, but it may also be the difference in the methods utilised for the statistical analysis: in the current analysis, the effect of interaction with axitinib dose titration versus placebo titration was investigated.

It had been speculated that aggressive axitinib dose increases might result in increased drug-related toxicities and, consequently, early treatment discontinuation. However, our analyses uncovered that the shorter OS was not due to toxicity-induced early treatment discontinuation, but rather likely to patient baseline characteristics. Up until now it has been unclear whether there are any baseline patient characteristics other than the dose titration criteria that were applied to axitinib clinical trials that should be considered when selecting patients for axitinib treatment with dose titration. The results of the current 
analyses may be helpful for physicians to potentially determine prospective patients who may receive clinical benefit from axitinib dose titration.

The current study had some limitations. The first limitation was the retrospective exploratory nature of the current analysis. In addition, the baseline patient characteristics which were not stratification factors in the original study were evaluated. Another is that in the current study, calcium concentration, which is one of the MSKCC risk factors in mRCC, was not collected and, hence, its impact on OS in patients with titrated axitinib doses could not be evaluated. Also, due to the relatively small sample size, the current analyses lacked the power to draw definitive conclusions. The current analysis included the evaluation of the effect of axitinib versus placebo titration on OS and thus, factors identified here are potentially predictive of survival with axitinib dose titration.

\section{Conclusions}

The exploratory analysis of the data from the randomised phase II study of axitinib titration in treatment-naïve patients with $\mathrm{mRCC}$ found that patients with $\geq 1$ year from histopathological diagnosis to treatment and $\geq$ LLN baseline haemoglobin level may potentially achieve survival benefit from the axitinib dose titration. These proposed baseline characteristics predictive of OS may help identify patients with $\mathrm{mRCC}$ who would likely benefit from axitinib dose titration.

\section{Additional files}

Additional file 1: Table presenting "Baseline characteristics of patients with OS $\geq 24$ versus $<24$ months in the placebo titration arm." (PDF $116 \mathrm{~kb}$ )

Additional file 2: Table presenting "Drug exposure in patients with OS $\geq 24$ versus $<24$ months in the placebo titration arm." (PDF 65 kb)

Additional file 3: Table presenting "Reasons for treatment discontinuation of patients with $O S \geq 24$ versus $<24$ months in the placebo titration arm." (PDF 65 kb)

Additional file 4: Table presenting "Common, all-causality adverse events reported in patients with $O S \geq 24$ versus $<24$ months in the placebo titration arm." (PDF $73 \mathrm{~kb}$ )

Additional file 5: Table presenting "Multivariate analysis of patient baseline characteristics for the effect of interaction with axitinib titration on OS." (PDF $105 \mathrm{~kb}$ )

\section{Abbreviations}

AE: Adverse event; bid: Twice daily; BP: Blood pressure; Cl: Confidence interval; ECOG PS: Eastern Cooperative Oncology Group performance status; HR: Hazard ratio; LLN: Lower limit of normal; mRCC: Metastatic renal cell carcinoma; OS: Overall survival; PFS: Progression-free survival; RECIST: Response Evaluation Criteria in Solid Tumours; ULN: Upper limit of normal; VEGF: Vascular endothelial growth factor

\section{Acknowledgments}

Medical writing support was provided by Mariko Nagashima, PhD, of Engage Scientific Solutions (Southport, CT, USA), and was funded by Pfizer.

\section{Funding}

This study was sponsored by Pfizer. Pfizer was responsible for the design of the study and collection, analysis, and interpretation of the data. Medical writing support was provided by Mariko Nagashima, PhD, of Engage Scientific Solutions (Southport, CT, USA), and was funded by Pfizer.

\section{Availability of data and materials}

Upon request, and subject to certain criteria, conditions and exceptions (see https://www.pfizer.com/science/clinical-trials/trial-data-and-results for more information), Pfizer will provide access to individual de-identified participant data from Pfizer-sponsored global interventional clinical studies conducted for medicines, vaccines and medical devices (1) for indications that have been approved in the US and/or EU or (2) in programs that have been terminated (i.e., development for all indications has been discontinued). Pfizer will also consider requests for the protocol, data dictionary, and statistical analysis plan. Data may be requested from Pfizer trials 24 months after study completion. The de-identified participant data will be made available to researchers whose proposals meet the research criteria and other conditions, and for which an exception does not apply, via a secure portal. To gain access, data requestors must enter into a data access agreement with Pfizer.

\section{Authors' contributions}

$A H B$ and $B I R$ participated in the conception or design of the study. BIR, $H U$, $M O, N S, T H$, and $Y T$ contributed to the acquisition of data, and AHB, BIR, YF, $Y K, Y T$, and $Y U$ contributed to the analysis and interpretation of data. All authors revised the manuscript critically for important intellectual content, were responsible for ensuring the accuracy and integrity of the content, and approved the final version for publication.

\section{Authors' information}

None

\section{Ethics approval and consent to participate}

The study protocol and patient informed consent form were approved by the institutional review board or independent ethics committee at each centre. The institutional review boards or independent ethics committees included Eticka komise, Multicenticka eticka komise Fakultni nemocnice Olomouc, Eticka komise Fakultni nemocnice Na Bulovce, Eticka komise, and Masarykuv onkologicky usta y (Czech Republic); Ethikkommission des Fachbereichs Medizin der Johann Wolfgang (Germany); Yamagata University Hospital IRB, Kinki University Hospital IRB, Keio University Hospital IRB, Tokushima University Hospital IRB, Kyushu University Hospital IRB, Sapporo Medical University Hospital IRB, Hokkaido University Hospital IRB, Chiba Cancer Centre IRB, Hamamatsu University School of Medicine, University Hospital IRB, Kobe University Hospital IRB, Nagoya University Hospital IRB, Akita University Hospital IRB, Japanese Foundation For Cancer Research Cancer Institute Hospital IRB, National Cancer Centre IRB, and Nagasaki University Hospital IRB (Japan); Ethics Council at the Ministry of Healthcare and Social Development of Russian Federation, Local Ethics Committee at Russian Research Centre of Roentgenology and Radiology, Ethics Committee, Russian Oncological Research Centre n.a. Blokhin RAMS, Ethics Committee at Samara Regional Clinical Oncology Dispensary, Local ethical committee Institution of Russian Academy of Medical Sciences Medical Radiology Research Centre of RAMS, Ethics Committee Leningrad Regional Oncology Dispensary, Ethics Committee at the City Clinical Oncology Dispensary of Saint- Petersburg, and Ethics Committee at the Federal Service on Surveillance in Healthcare and Social Development (Russian Federation); CEIC AREA 5-Hospital Universitario La Paz Ethics Committee of Clinic Hospital General, Hospital Gregorio Marañon Comite Etico de Investigacion Clinica, and Hospital Universitario La Paz Ethics Committee of Clinic Investigation (Spain); Nebraska Methodist Hospital Institutional Review Board, Office for Human Research Studies Dana Farber Cancer Institute, Cleveland Clinic I nstitutional Review Board, University of Nebraska Medical Centre Institutional Review Board, The Johns Hopkins Medicine Institutional Review Board, Quorurn Review, Schulman Associates Institutional Review Board, Inc., IUPUI Institutional Review Board, Indiana University Institutional Review Board, Western Institutional Review Board, Washington University School of Medicine Human Research Protection Office (IRB), University of Texas M.D. Anderson Cancer Centre Surveillance Committee FWA-363, Oregon Health and Science University Research Integrity Office (ORIO) Institutional Review 
Board, and University of Cincinnati Institutional Review Board (USA). Written informed consent was obtained from each patient.

\section{Consent for publication}

Not applicable since the manuscript does not contain any individual patient data.

\section{Competing interests}

YT has received research funding from Pfizer, Ono, Takeda and Astellas, and honoraria from Pfizer, Novartis, Ono, Astellas and Bristol-Myers Squibb. HU has received research funding from Pfizer and Novartis, and honoraria from Pfizer, Bayer, Novartis, Ono and Bristol-Myers Squibb. MO has received research funding and honoraria from Pfizer, Novartis and Ono, and honoraria from Bayer. NS has received research funding from Pfizer, Ono and Astellas, and honoraria from Pfizer, Bayer, Novartis and GlaxoSmithKline. TH has received research funding and honoraria from Pfizer, Novartis and Bayer. YF, $Y K$, and $Y U$ are employed by Pfizer R\&D Japan and YU owns stock in Pfizer. AHB is employed by and owns stock in Pfizer. BIR has served as a consultant for and received research funding from Pfizer.

\section{Publisher's Note}

Springer Nature remains neutral with regard to jurisdictional claims in published maps and institutional affiliations.

\section{Author details}

'Department of Urology, Department of Molecular Oncology, Niigata University Graduate School of Medical and Dental Sciences, Asahimachi 1-757, Niigata 951-8510, Japan. ${ }^{2}$ Department of Urology, Kindai University Faculty of Medicine, Osaka, Japan. ${ }^{3}$ Department of Urology, Keio University School of Medicine, Tokyo, Japan. ${ }^{4}$ Department of Urology, Hokkaido University Graduate School of Medicine, Sapporo, Hokkaido, Japan. ${ }^{5}$ Department of Urology, Akita University School of Medicine, Akita, Japan. ${ }^{6}$ Pfizer Japan Inc, Tokyo, Japan. ${ }^{7}$ Pfizer Oncology, San Diego, CA, USA. ${ }^{8}$ Department of Solid Tumour Oncology, Cleveland Clinic Taussig Cancer Institute, Cleveland, $\mathrm{OH}$, USA

\section{Received: 11 October 2017 Accepted: 13 December 2018}

\section{Published online: 07 January 2019}

\section{References}

1. Inlyta (axitinib) US prescribing information. Pfizer Inc, New York, NY. Pfizer Inc. 2014. http://labeling.pfizer.com/ShowLabeling.aspx?id=759. Accessed 20 July 2017.

2. Rini Bl, Melichar B, Ueda T, Grunwald V, Fishman MN, Arranz JA, Bair AH Pithavala YK, Andrews Gl, Pavlov D, Kim S, Jonasch E. Axitinib with or without dose titration for first-line metastatic renal-cell carcinoma: a randomised double-blind phase 2 trial. Lancet Oncol. 2013;14(12):1233-42.

3. Rini BI, Tomita Y, Melichar B, Ueda T, Grunwald V, Fishman MN, Uemura H, Oya M, Bair AH, Andrews Gl, Rosbrook B, Jonasch E. Overall survival analysis from a randomized phase II study of axitinib with or without dose titration in first-line metastatic renal cell carcinoma. Clin Genitourin Cancer. 2016; 14(6):499-503.

4. Motzer R, Bacik J, Murphy BA, Russo P, Mazumdar M. Interferon-alfa as a comparative treatment for clinical trials of new therapies against advanced renal cell carcinoma. J Clin Oncol. 2002:20(1):289-96.

5. Heng DY, Xie W, Regan MM, Warren MA, Golshayan AR, Sahi C, Eigl BJ, Ruether JD, Cheng T, North S, Venner P, Knox JJ, Chi KN, Kollmannsberger C, McDermott DF, Oh WK, Atkins MB, Bukowski RM, Rini Bl, Choueiri TK. Prognostic factors for overall survival in patients with metastatic renal cell carcinoma treated with vascular endothelial growth factor-targeted agents: results from a large, multicenter study. J Clin Oncol. 2009;27(34):5794-9.

6. Motzer RJ, Escudier B, Bukowski R, Rini Bl, Hutson TE, Barrios CH, Lin X, Fly K, Matczak E, Gore ME. Prognostic factors for survival in 1059 patients treated with sunitinib for metastatic renal cell carcinoma. Br J Cancer. 2013;108(12):2470-7.

7. Heng DY, Xie W, Regan MM, Harshman LC, Bjarnason GA, Vaishampayan UN, Mackenzie M, Wood L, Donskov F, Tan MH, Rha SY, Agarwal N, Kollmannsberger C, Rini Bl, Choueiri TK. External validation and comparison with other models of the international metastatic renal-cell carcinoma database consortium prognostic model: a population-based study. Lancet Oncol. 2013;14(2):141-8.
8. Tomita Y, Fukasawa S, Oya M, Uemura H, Shinohara N, Habuchi T, Rini Bl, Chen Y, Bair AH, Ozono S, Naito S, Akaza H. Key predictive factors for efficacy of axitinib in first-line metastatic renal cell carcinoma: subgroup analysis in Japanese patients from a randomized, double-blind phase II study. Jpn J Clin Oncol. 2016;46(11):1031-41.

9. Oya M, Tomita Y, Fukasawa S, Shinohara N, Habuchi T, Rini Bl, Fujii Y, Kamei Y, Umeyama Y, Bair AH, Uemura H. Overall survival of 1st-line axitinib in metastatic renal cell carcinoma: Japanese subgroup analysis from phase II study. Cancer Sci. 2017;108(6):1231-9.

10. Motzer RJ, Escudier B, Tomczak P, Hutson TE, Michaelson MD, Negrier S, Oudard S, Gore ME, Tarazi J, Hariharan S, Chen C, Rosbrook B, Kim S, Rini BI. Axitinib versus sorafenib as second-line treatment for advanced renal cell carcinoma: overall survival analysis and updated results from a randomised phase 3 trial. Lancet Oncol. 2013;14(6):552-62.

11. Naito S, Yamamoto N, Takayama T, Muramoto M, Shinohara N, Nishiyama K, Takahashi A, Maruyama R, Saika T, Hoshi S, Nagao K, Yamamoto S, Sugimura I, Uemura H, Koga S, Takahashi M, Ito F, Ozono S, Terachi T, Tomita Y. Prognosis of Japanese metastatic renal cell carcinoma patients in the cytokine era: a cooperative group report of 1463 patients. Eur Urol. 2010; 57(2):317-25.

12. Beuselinck B, Vano YA, Oudard S, Wolter P, De Smet R, Depoorter $L$, Teghom C, Karadimou A, Zucman-Rossi J, Debruyne PR, Van Poppel H, Joniau S, Lerut E, Strijbos M, Dumez H, Paridaens R, Van Calster B, Schoffsk P. Prognostic impact of baseline serum C-reactive protein in patients with metastatic renal cell carcinoma (RCC) treated with sunitinib. BJU Int. 2014; 114(1):81-9.

13. Teishima J, Kobatake K, Hayashi T, Seno Y, Ikeda K, Nagamatsu H, Hieda K, Shoji K, Miyamoto K, Inoue S, Kobayashi K, Ohara S, Kajiwara M, Matsubara A. Prognostic significance of $\mathrm{C}$-reactive protein in patients with intermediate-risk metastatic renal cell carcinoma treated with molecular targeted therapy. Oncol Lett. 2014;8(2):881-5.

\section{Ready to submit your research? Choose BMC and benefit from:}

- fast, convenient online submission

- thorough peer review by experienced researchers in your field

- rapid publication on acceptance

- support for research data, including large and complex data types

- gold Open Access which fosters wider collaboration and increased citations

- maximum visibility for your research: over $100 \mathrm{M}$ website views per year

At $\mathrm{BMC}$, research is always in progress.

Learn more biomedcentral.com/submissions 